\title{
Contexto de Produção e o Estabelecimento da Coerência na Escrita de Histórias por Crianças
}

\author{
Contexts of Textual Production and the Construction of Coherence \\ in Stories Written by Children
}

\author{
Ana Paula Perdigão Pessoa*,, Jane Correa ${ }^{a} \&$ Alina Spinillo ${ }^{b}$ \\ ${ }^{a}$ Universidade Federal do Rio de Janeiro \& ${ }^{b}$ Universidade Federal de Pernambuco
}

\begin{abstract}
Resumo
O presente artigo examina a influência da escolaridade e do contexto de produção textual na escrita de histórias por crianças das primeiras séries do Ensino Fundamental. Na primeira condição, as crianças produziram uma história inventada por elas. Na segunda, as crianças foram orientadas a reproduzirem por escrito um conto clássico infantil. As histórias foram classificadas segundo níveis distintos e crescentes de complexidade narrativa e de coerência. A escolaridade e as condições de produção influenciaram o estabelecimento da coerência textual, sendo que o efeito do contexto de produção sobre a escrita de história não foi o mesmo para todas as crianças. A sensibilidade ao contexto de produção estaria relacionada ao grau de domínio de um esquema narrativo de histórias apresentado pela criança.
\end{abstract}

Palavras-chave: Linguagem Escrita; Narrativas; Estrutura do Texto.

\begin{abstract}
This study examines the influence of schooling and the context of textual production on stories written by $1^{\text {st }}$ and $2^{\text {nd }}$ graders. In the first condition, children were asked to write original stories. In the second condition, they were asked to reproduce in writing a classical tale for children. The stories were classified according to the complexity and coherence of the narrative. Results indicate that schooling and condition of text production influenced the establishment of textual coherence. However, the effect of the contexts of textual production on children's writing was not the same for all children. Sensitivity to the contexts of text production seemed to have been related to children's awareness of narrative schema. Keywords: Written Language; Narrative; Text Structure.
\end{abstract}

Através da escrita as pessoas interagem umas com as outras trocando informações, conhecimentos e experiências. Utilizar a escrita como meio de comunicação é uma prática bastante complexa que exige daquele que escreve a tomada de importantes decisões com relação ao texto a ser produzido (Garcez, 2002). A coerência é uma das propriedades da textualidade que faz com que o texto não se reduza a uma simples seqüência de enunciados (palavras e frases). Embora de difícil conceituação, a coerência pode ser considerada uma conexão de natureza conceitual-cognitiva que se manifesta macrotextualmente. Trata-se de uma propriedade que confere sentido e unidade ao texto (Koch \& Travaglia, 2003, 2005;
Marcuschi, 1983). Segundo Beaugrande e Dressler (1981), a continuidade de sentidos é o fundamento da coerência, sendo um produto da combinação de conceitos e relações dentro de uma rede composta por tópicos mantidos e conectados ao longo da narração.

A literatura apresenta duas formas distintas de se classificar os tipos de coerência. A primeira refere-se a um enfoque marcadamente extratextual que toma por base a distinção entre comunicação oral e comunicação escrita, enfatizando a situação de produção e de recepção do texto. Os estudos que se inserem nesta perspectiva tendem a investigar a coerência em contextos de interação face-aface em que os textos são oralmente produzidos em 
situações de conversação (e.g., Coates, 1992; Goodwin, 1992; Marcuschi, 1998). A segunda forma de classificação refere-se a um enfoque marcadamente intratextual que enfatiza os aspectos relativos ao texto em si, como os aspectos micro e macrolingüísticos (e.g., van Dijk \& Kintsch, 1983; Hudson \& Shapiro, 1991; Spinillo \& Martins, 1997). Esta segunda perspectiva é adotada no presente estudo que examina o estabelecimento da coerência a partir da produção escrita de textos.

Os aspectos micro e macrolingüísticos podem ser entendidos como fatores de coerência. Segundo alguns pesquisadores (Hudson \& Shapiro, 1991; Spinillo, 2001), o conhecimento microlinguístico envolve as relações coesivas estabelecidas pelo produtor, tendo papel importante no estabelecimento da coerência uma vez que auxiliam a manter o tópico do discurso e a dar continuidade e sequiência à narração. Assim, a coesão auxilia na criação de mecanismos para o estabelecimento da coerência. Os fatores macrolingüísticos referem-se à macroestrutura do texto. Desta forma, uma estrutura temático-semântica global define sua significação como um todo. Spinillo e Martins (1997) afirmam que, no caso de histórias, a coerência estaria relacionada à presença de seus componentes estruturais (cena, personagens, cadeia de eventos/tramas, desfecho e resolução da trama), sendo necessário incorporar esses elementos a um enredo coerente $\mathrm{e}$ lógico, com relações temporais e de causalidade que marcam a história.

A maioria das pesquisas na área examina a coerência a partir da perspectiva do receptor do texto (seja ele leitor ou ouvinte). Aproximam-se, neste sentido, à própria compreensão textual. Entretanto, é igualmente importante analisar a coerência na perspectiva do produtor do texto (Spinillo \& Martins, 1997). Pesquisas que investigam a coerência a partir da perspectiva do produtor são, no entanto, raras (e.g., Bennett-Kastor, 1983; Gonçalves \& Dias, 2003; Spinillo \& Martins, 1997). Um exemplo é a pesquisa realizada por Spinillo e Martins (1997), que investigou como crianças de 6-7 anos (com diferentes níveis de escolaridade: pré-escolar, alfabetização e $1^{a}$ série do Ensino Fundamental) estabelecem a coerência ao produzir oralmente uma história. As produções foram analisadas em função de indicadores específicos relativos à coerência que, agrupados em um sistema de análise, expressavam diferentes níveis no estabelecimento da coerência. Os indicadores adotados por Spinillo e Martins tinham por base um enfoque macrotextual em que os princípios de constituição de histórias eram: (a) a manutenção do tópico sobre o qual versa a história e ao redor do qual os eventos se articulam; (b) a manutenção dos personagens que estão engajados nos eventos; (c) a relação entre os eventos narrados que precisam estar conectados entre si pelos personagens, e que contribuem para a unidade da narração; e (d) a relação entre os eventos presentes no desenvolvimento da história e seu desfecho. A partir destes indicadores, os autores criaram um sistema de análise baseado em níveis hierárquicos quanto ao estabelecimento da coerência na produção de histórias. De maneira geral, os dados mostraram haver uma progressão no estabelecimento da coerência. Além disso, apontaram a escolaridade, particularmente a aquisição da leitura e da escrita, como fator decisivo nesta progressão, visto que crianças alfabetizadas tendiam a produzir histórias mais coerentes do que as de mesma idade, porém ainda não alfabetizadas.

Gonçalves e Dias (2003) replicaram o estudo de Spinillo e Martins (1997) em jovens e adultos participantes de um programa educacional (EJA) que tinha por objetivo alfabetizar pessoas fora da faixa etária regular. Adotando o mesmo sistema de análise elaborado pelos autores do estudo original, as pesquisadoras observaram que a aquisição da leitura e da escrita era fator determinante na produção de histórias coerentes, mesmo entre jovens e adultos.

Além da escolaridade, outros fatores mostram-se importantes no estabelecimento da coerência na produção de histórias. Spinillo (2001) aponta para o efeito do contexto de produção sobre a qualidade narrativa de histórias produzidas por crianças. O efeito dessas variações tem sido analisado em relação à produção oral, sendo pouco examinado em relação à escrita de histórias. As crianças são sensíveis às condições de produção, de forma que a habilidade narrativa pode emergir em uma situação, porém não em outra. Um exemplo disso é a pesquisa realizada por Lins e Silva e Spinillo (2000) em que crianças de primeira à quarta série do ensino fundamental foram solicitadas a escrever histórias em quatro condições distintas: produção livre; produção oral/escrita; produção a partir de seqüência de gravuras; e reprodução de uma história ouvida. Os dados mostraram que as condições experimentais tiveram um efeito sobre as produções; as histórias com uma estrutura narrativa mais elaborada eram as produzidas a partir da sequiência de gravuras e a partir da história ouvida. Este efeito não foi observado entre as crianças das séries mais adiantadas, cujas histórias apresentavam uma estrutura narrativa elaborada em todas as condições de produção.

Conforme a literatura na área indica, as condições de produção escrita que oferecem algum apoio à criança, seja visual, através da apresentação de uma seqüência de gravuras (Lins e Silva \& Spinillo, 2000; Shapiro \& Hudson, 1991), ou lingüístico, por meio da reprodução de uma história lida anteriormente (Lins e Silva \& Spinillo, 2000) tendem a propiciar a produção de textos mais organizados estruturalmente do que condições que não oferecem qualquer apoio, como, por exemplo, a situação de produção livre. Cabe perguntar se isto seria também observado em relação ao estabelecimento da coerência.

No que tange ao estabelecimento da coerência, o presente estudo trata de duas condições de produção escrita distintas: a produção livre, que não conta com qualquer apoio (visual ou lingüístico) e a reprodução, que conta com apoio lingüístico. A produção livre é uma atividade 
que demanda do produtor a geração de idéias a respeito do tópico a ser narrado, da cena, dos personagens, dos eventos e do desfecho. A reprodução escrita, por outro lado, fornece todos esses elementos, ou seja, as características estruturais da história a ser reproduzida, bem como um apoio lingüístico (Cardoso, 2000; Lins e Silva \& Spinillo, 2000; Nóbrega, 1997; Pontecorvo \& Ferreiro, 1996; Teberosky, 1995). Surge, então nova indagação: poderia a reprodução escrita auxiliar a produção de textos coerentes?

Apesar de tais diferenças entre a escrita livre e a reprodução escrita de história, não há, ainda, um conjunto de evidências empíricas que mostrem que tais condições possam produzir diferenças significativas na escrita de histórias coerentes por crianças nos anos iniciais de sua escolarização. Cardoso (2000) demonstra que, em linhas gerais, crianças cursando a $1^{\mathrm{a}}$ série do ensino fundamental tiveram melhor desempenho (no que se refere à capacidade de explicitação textual) na tarefa de reprodução escrita de história do que na situação de relato de fato vivido. Por outro lado, Pontecorvo e Morani (1996) não relatam diferenças significativas na produção de histórias por crianças de 6 e 7 anos nas condições de produção livre ou de reprodução escrita. Apesar de Lins e Silva e Spinillo (2000) mostrarem que o contexto de produção que oferece um apoio lingüístico gera a escrita de histórias mais organizadas, a influência dos contextos de reprodução escrita e escrita livre não foi explorada para cada uma das séries separadamente. As autoras privilegiaram, na análise da relação entre série e condições de produção, o contraste entre os contextos que oferecem apoio, seja ele lingüístico ou visual, e os que não oferecem tal apoio. Desta forma, foram agrupados os resultados referentes às condições de reprodução escrita de história e produção a partir de seqüência de gravuras (contextos que oferecem apoio) a fim de compará-los com contextos de escrita livre e produção oral/escrita, sem apoio lingüístico. Neste sentido, a possível diferença entre a reprodução escrita e a escrita livre, no que concerne ao estabelecimento da coerência, é aspecto ainda não explorado na literatura, visto que os estudos anteriores se dedicaram a examinar a estrutura narrativa de história.

O presente estudo procurou, então, investigar o efeito das condições de produção escrita livre e reprodução escrita sobre o estabelecimento da coerência na escrita de histórias por crianças nos primeiros anos do ensino fundamental. Acredita-se que a situação de reprodução escrita de história, por oferecer uma referência de estrutura narrativa, suscitaria a produção de um texto mais coerente do que a situação de escrita livre, que não oferece tal referência. Com relação à interação entre os fatores escolaridade e contexto de produção, o efeito do contexto na elaboração do texto não seria o mesmo para as duas séries investigadas. Haveria menor susceptibilidade às condições de produção conforme o aumento da escolaridade das crianças.

\section{Método}

\section{Participantes}

Participaram da pesquisa 108 crianças matriculadas regularmente nas séries iniciais do ensino fundamental em uma escola da rede pública situada em um bairro de classe média da cidade do Rio de Janeiro. Do total de participantes, 56 crianças cursavam o $2^{\circ}$. ano (24 do sexo feminino e 32 do sexo masculino, sendo a média de idade 7 anos e 5 meses e desvio-padrão 5 meses) e 52 crianças cursavam a $3^{\circ}$. ano (27 do sexo feminino e 25 do sexo masculino, sendo a média de idade 8 anos e 5 meses e o desvio-padrão 4 meses).

\section{Procedimentos}

As crianças foram solicitadas a produzir, como parte de suas atividades de sala de aula, dois textos escritos: uma história livre (Condição 1) e a reprodução de um conto infantil (Condição 2). Inicialmente foi pedido a todas as crianças que escrevessem uma história inventada por elas. Na semana seguinte, foi lido o conto infantil Chapeuzinho Vermelho e pedido a todas as crianças que reproduzissem por escrito o conto lido. A tarefa de reprodução escrita de história foi pedida posteriormente à tarefa de escrita livre, a fim de evitar possível influência da escrita do conto sobre a produção livre. A opção por utilizar na tarefa de reprodução um conto clássico infantil justifica-se pelo fato do conto - ao contrário de uma história qualquer - fazer parte do imaginário infantil e ser mais familiar que outras histórias (Bettelheim, 1979).

\section{Resultados}

As histórias foram classificadas conforme a categorização proposta por Spinillo e Martins (1997), que expressa quatro níveis distintos e crescentes de coerência textual. Seguem abaixo a descrição de cada nível e a apresentação de alguns exemplos das histórias escritas pelas crianças nas duas condições de produção investigados: escrita livre ou reprodução escrita de história. Nos exemplos que se seguem, as histórias foram transcritas respeitando-se a forma como foram escritas pelas crianças, mantendo-se, inclusive, as transgressões ortográficas por elas realizadas.

\section{Nivel I}

As histórias incluídas neste nível apresentam eventos que se sucedem de forma não conectada ao longo do texto, dificultando a identificação de um tema central. São histórias que terminam abruptamente.

\section{Condição 1 - Escrita Livre}

\section{A foresta em camtada}

Era uma veis uma foresta que miguen sabia que ela era uma foresta em camtada todos pensavam que ela era normao mais ela era esperiente demas 
um dia ela decapareseu é eles não pasava perto porque voce ia ir com ela ai um dia ela voutou e nimguenemtor so o caroto é não a comteceu nada e dodos eles emtarro é ele levou eles para ver o chocolate ele morava numa casa de chocolate ele não podia ir parala mais ele podia ir parala na fabirca de chocolate mais ele dice que ele era mageco e cempre ia ver ele

\section{Condição 2 - Reprodução Escrita do Conto}

\section{Chapeuzinho vermelho}

O chapeuzinho vermenho vai ao parque borque o chapeuzinho vermenho ai o lobumal ai o lobumal queria ser um omeno borque a chapelzino vermelho vai ao barque e vigol igal um omeno ai eles voram verires para sempre e fim.

\section{Nível II}

Neste nível, as histórias caracterizam-se por eventos que possuem alguma relação entre si. Porém, nem sempre é possível identificar qual o evento principal. Em sua maioria, as histórias não trazem um desfecho, sendo encerradas abruptamente. Nos casos em que o desfecho existe, este não apresenta uma ligação clara com os eventos anteriormente narrados. Desta forma, as histórias deste nível apresentam uma organização ainda pouco articulada, havendo um certo comprometimento na continuidade de sentidos.

\section{Condição 1- Escrita Livre}

\section{As serreias}

Era uma vez três serreias que vivian no mar, mais o mar tinha um segredo. Que as serreias não sabiam. mergulhara e acharão o segredo, era um baú cheio de ouro. Mais o mar guarda uma historia que as serreias não sabiam.

\section{Condição 2- Reprodução Escrita do Conto}

\section{Chapeuzinho Vermelho}

Era uma vez a chapeuzinho vermelho um dia ela tava levando uma sesta cheia de bolo, salgado e muita comida Um dia apareceu um lobo e falou o minina que ten neça sesta comida para a minha vovóe o lobo foi pelo atalho.

\section{Nível III}

As histórias classificadas neste nível apresentam eventos que se sucedem de forma consideravelmente interligada, sendo o evento principal facilmente identificado. Nota-se a presença de um desfecho que, apesar de apresentar uma relação com o desenvolvimento da história, não se articula de forma precisa com o evento principal e a situação-problema. Este fato provoca uma lacuna na sequiência narrativa ao final da história.

\section{Condição 1 - Escrita Livre}

\section{A menina do gropo}

as três menina uma delas o

nome é lili. a lili era muito e

emgrasada e um dia, a lala paguntou

pra lili por que você não gosta de brinca

lili não respondeu e com tinou andar

logo condo chegou a mãe falou lili

por que você estar triste e por que o eu

dente estar mole e estou com medo

e estou com medo de fica cêm demte $e$

mechamare de janelona

um dia, lili açodou e logo foi no

espelho e o demte cai e a lili ficou

a legre de mas e ficou feliz

\section{Condição 2 - Reprodução Escrita do Conto}

\section{Chapeuzinho Vermelho}

Era uma vez...

Uma menininha que se chamava cha

Peuzinho Vermelho porque ela tinha um

Vestido vermelho, uma bota vermelho e uma

Capa vermelha.

Um dia a mãe dela pidio para ela

ir levar doces na casa de sua avó...

Sua mãe dice para ela não fala

com ninguém. Ela dice - tabom mamãe.

I aconteceu que apareceu um lobo.

I ele perguntou. - para onde você esta

indo? Chapeuzinho respondeu. - estou

indo pra casa da minha vovó

levar esis doces para minha vovó.

O lobo enrrolando. - va pelo caminho

curto que eu vou passea... Tabom...

Chegando mas rápido o lobo avan-

sou na vovó.

quando chapeuzinho chegou o lobo

ja estava arrumadinho para avan-

sa. A menina perguntou tudo

mas o lobo não escapou.

Nivel IV

Aqui as histórias se caracterizam por eventos coerentemente seqüenciados e articulados, com o evento principal identificável. O desfecho está claramente explicitado e também fortemente relacionado aos acontecimentos narrados, mantendo uma ligação estreita com o evento principal e a trama da história. As histórias deste nível consistem em produções bastante coerentes.

\section{Condição 1 - Escrita Livre}

\section{$O$ inverno de Carol}

Era uma vez uma menininha que adorava o inverno e se chamava Carol. Ela tinha seu gato peludo 
branquinho, carinhoso e com o pêlo bem longo e macio se chamava Nemo.

Um dia Carol e Nemo resolveram fazer uma casa de neve no meio da neve. Então eles foram fazer uma casa de neve mas nem repararam que foram muito longe de casa. Quando terminaram perceberam que estavam perdidos andaram, andaram, mas não acharam a sua verdadeira casa. Até eles ouvirem a buzina de um carro por sorte era o pai de Carol que levou ela para casa e ela contou o que tinha acontecido e ela nunca mas saiu sozinha.

E todos foram felizes para sempre.

\section{Condição 2 - Reprodução Escrita do Conto}

\section{Chapeuzinho Vermelho}

Era uma vez uma menina chamada

Chapeuzinho Vermelho. Se chamava assim

porque sempre usava um capuz vermelho.

Certo dia sua mãe mandou

Chapeuzinho Vermelho levar uns

doces para sua avó e falou:

- Não pare para falar com estranhos.

Pelo caminho ela encontrou um lo-

bo que a perguntou:

- Aonde vai com tanta pressa minha jovem?

- Vou para a casa da minha avó

entregar estes doces.

Respondeu Chapeuzinho.

- E onde mora sua avó?

Perguntou fingindo-se de bonzinho.

- Mora logo no fim deste bosque

Respondeu Chapeuzinho.

E o lobo se dirigiu para a casa

da vóvo no caminho mais curto.

Chegando lá bateu a porta:

- Toc, toc, toc...

- Quem é

(Vóvo perguntou.)

- Sou eu Chapeuzinho Vermelho!!

Respondeu o lobo fingindo-se de Chapéu-

zinho.

- Puxe a tranca.

(Vóvo respondeu.)

Quando entrou, engoliu a vovó inteirinha

Sem mastigar. Quando Chapeuzinho chegou

Na casa da Vóvo e bateu a porta:

-Toc, toc, toc...

-Quem é?

Perguntou o lobo fingindo-se de vovozinha.

- É a Chapeuzinho Vermelho sua netinha.

Respondeu ela.

Puxe a tranca.

O lobo respondeu.

Quando entrou perguntou:
- Nossa vovó que olhos que olhos grandes

são esses?

- São para te ver melhor.

Respondeu o lobo

- E esse nariz?

Perguntou Chapeuzinho.

- É para te cheirar.

Respondeu o lobo.

- E essa boca tão grande

Indagou Chapeuzinho.

-E para te comer

O lobo respondeu.

Nesse instante ele pulou em cima da menina, mas ela conseguiu escapar.

O caçador que estava passando ouviu

os gritos da menina e matou o lobo.

Rasgou a barriga do lobo e tirou a

vóvo vivinha

E foram felizes para sempre.

A classificação das histórias em cada um desses níveis foi realizada por dois juízes independentes, com índice de concordância de $89 \%$ na condição de reprodução escrita e de $91 \%$ na de produção livre. Os casos de discordâncias foram analisados por um terceiro juiz, também independente, cuja classificação foi considerada definitiva. A Tabela 1 apresenta a distribuição das histórias em cada nível de coerência por série e contexto de produção.

Tabela 1

Nivel de Coerência Segunda a Escolaridade e Contexto de Produção

$$
\begin{array}{cc}
2^{\circ} . \text { ano } & 3^{\circ} . \text { ano } \\
(n=56) & (n=52)
\end{array}
$$

\begin{tabular}{lcccc}
\hline $\begin{array}{l}\text { Níveis de } \\
\text { Coerência }\end{array}$ & $\begin{array}{c}\text { Escrita } \\
\text { Livre }\end{array}$ & $\begin{array}{c}\text { Reprodução } \\
\text { Escrita }\end{array}$ & $\begin{array}{c}\text { Escrita } \\
\text { Livre }\end{array}$ & $\begin{array}{c}\text { Reprodução } \\
\text { Escrita }\end{array}$ \\
\hline I & 23 & 18 & 6 & 2 \\
II & 41 & 25 & 21 & 12 \\
III & 16 & 18 & 23 & 21 \\
IV & 20 & 39 & 50 & 65 \\
\hline
\end{tabular}

Nota. Nível I: eventos desconectados; Nível II: eventos com certa relação, sem identificar o principal; Nível III: desfecho que não se articula com evento principal e situação-problema; Nível IV: história articulada.

Para efeito de análise, foram atribuídos de 1 a 4 pontos a cada história, em função de sua classificação em um dos quatro níveis acima descritos. Desta forma, quanto maior a pontuação atribuída, mais coerente era a história (ver Tabela 2). 
Tabela 2

Média dos Pontos Atribuídos às Histórias por Série e Condição

\begin{tabular}{lccc}
\hline & \multicolumn{2}{c}{ Condição } \\
\cline { 3 - 4 } & & $\begin{array}{c}\text { Escrita } \\
\text { Livre }\end{array}$ & $\begin{array}{c}\text { Reprodução } \\
\text { Escrita }\end{array}$ \\
\hline $2^{\circ}$. ano & $M$ & 2,32 & 2,79 \\
$(n=56)$ & $D P$ & 1,05 & 1,16 \\
$3^{\circ}$. ano & $M$ & 3,17 & 3,5 \\
$(n=52)$ & $D P$ & 0,96 & 0,78 \\
\hline
\end{tabular}

Os resultados da Análise de Variância revelam que a produção de histórias coerentes varia significativamente de acordo com a escolaridade $(F(1,106)=22,84 ; p<.001)$ : as crianças do $3^{\circ}$. ano produzem histórias mais coerentes do que as crianças do $2^{\circ}$. ano. Os resultados mostram também diferença estatisticamente significativa relacionada à condição de produção $(F(1,106)=15,24 ; p=; p<$ $.001)$. Isto ocorreu porque as histórias produzidas na Condição 2 (reprodução escrita) tinham um nível maior de coerência do que aquelas escrita na Condição 1 (escrita livre). A interação entre série e condição não foi, por outro lado, significativa $(F(1,106)=.45, p=.49)$.

\section{Análise do Desempenho Individual das Crianças}

Lins e Silva e Spinillo (2000) sugerem que o efeito do contexto sobre a produção escrita não é o mesmo em estudantes de séries diferentes ou mesmo em crianças de uma mesma série. A susceptibilidade estaria, pois, relacionada ao grau de domínio do esquema narrativo de história pelas crianças. Em outras palavras, de acordo com grau de desenvolvimento de suas habilidades narrativas, o desempenho escrito da criança poderia variar de uma condição de produção a outra. Realizamos, então, a análise do desempenho individual das crianças em função do domínio do esquema narrativo nas duas condições de produção. De maneira similar àquela proposta por essas autoras, a classificação pode ser descrita como se segue:

Domínio 1 do Desenvolvimento do Esquema Narrativo. As narrativas produzidas pelas crianças haviam sido classificadas, quanto ao nível de coerência alcançado, no Nível I ou Nível II nas duas condições de produção. Estas crianças eram pouco susceptíveis a variações nas condições de produção.

Domínio 2 do Desenvolvimento do Esquema Narrativo. As histórias produzidas pelas crianças foram classificadas no Nível I ou II em uma condição e no Nível III ou IV em outra condição. Estas crianças eram sensíveis a variações experimentais.

Domínio 3 do Desenvolvimento do Esquema Narrativo. As crianças produziam histórias coerentes nas duas condições (classificadas no Nível III e IV). Estas crian- ças eram pouco susceptíveis às variações nas condições de produção.

As crianças que, em relação à construção do esquema narrativo, foram classificadas nos domínios 1 e 3 foram pouco susceptíveis a variações nas condições de produção. Porém esta estabilidade tem razões distintas. As crianças no domínio 1 são estáveis porque são igualmente elementares no estabelecimento da coerência nas duas situações de produção. Por sua vez, as crianças no domínio 3 são estáveis porque são igualmente capazes de estabelecer a coerência em ambas as situações. No domínio 3, as crianças apresentam uma capacidade de produção narrativa mais elaborada de forma que suas histórias são coerentes independentemente da condição de produção. Assim, razões distintas regem o comportamento das crianças nestes grupos, evidenciando diferentes momentos no desenvolvimento psicolingüístico. Por sua vez, as crianças que se encontram no Domínio 2 do desenvolvimento do esquema narrativo parecem estar em um momento intermediário dessa aquisição, de forma que o nível de coerência de suas histórias variam em função da condição de produção do texto. Na Tabela 3 consta a distribuição de crianças em cada domínio do desenvolvimento do esquema narrativo em função da escolaridade.

Tabela 3

Porcentagem de Crianças em Cada Domínio de Desenvolvimento do Esquema Narrativo segundo sua Escolaridade

\begin{tabular}{lcc}
\hline Esquema Narrativo & $\begin{array}{c}1^{a} \text { Série } \\
(\mathrm{n}=56)\end{array}$ & $\begin{array}{l}2^{\text {a Série }} \\
(\mathrm{n}=52)\end{array}$ \\
\hline Domínio 1 & 34 & 10 \\
Domínio 2 & 39 & 21 \\
Domínio 3 & 27 & 69 \\
\hline
\end{tabular}

Foram identificadas diferenças significativas entre as séries quanto ao domínio do esquema narrativo segundo o qual as crianças foram agrupadas $\left(\chi^{2}=20,36, p<0,001\right)$ : as crianças do $2^{\circ}$. ano tendiam a concentrar-se nos Domínios 1 (34\%) e 2 (39\%); enquanto a maioria das crianças do $3^{\circ}$. ano $(69 \%)$ se concentrava no Domínio 3. Esse dado sugere que as crianças do $3^{\circ}$. ano apresentam níveis de coerência mais elaborados e estáveis do que as do $2^{\circ}$. ano. Este domínio na produção de histórias coerentes se manifesta em ambas condições.

Como é interesse deste estudo explorar qual das duas condições mais contribui para o estabelecimento da coerência textual, torna-se importante examinar de forma mais detalhada as crianças classificadas quanto ao desenvolvimento do esquema narrativo no Domínio 2. As histórias produzidas por estas crianças variavam quanto ao nível de coerência que apresentavam em função das condições de produção. A Tabela 4 refere-se às crianças classificadas no Domínio 2 de desenvolvimento do es- 
quema narrativo de ambas as séries, tomadas de forma conjunta (correspondendo a $31 \%$ de todos os participantes do estudo).

Tabela 4

Distribuição das Crianças no Domínio 2 do Desenvolvimento do Esquema Narrativo em Função dos Níveis de Coerência de Suas Histórias nas Duas Condições de Produção

\begin{tabular}{llcrr}
\hline & \multicolumn{4}{c}{$\begin{array}{c}\text { Reprodução Escrita } \\
\text { Niveis de Coerência }\end{array}$} \\
\hline $\begin{array}{l}\text { Escrita Livre } \\
\text { Niveis de Coerência }\end{array}$ & I & II & III & IV \\
I & & & & \\
II & 0 & 0 & 4 & 1 \\
III & 0 & 0 & 9 & 12 \\
IV & 1 & 2 & 0 & 0 \\
\hline
\end{tabular}

Nota. Nível I: eventos desconectados; Nível II: eventos com certa relação, sem identificar o principal; Nível III: desfecho que não se articula com evento principal e situação-problema; Nível IV: história articulada.

Em função dos valores muito baixos das células, não foi possível aplicar qualquer tratamento estatístico. Entretanto, observa-se que apenas sete crianças tiveram uma produção bem mais elaborada na Escrita Livre (Níveis III e IV) do que na Reprodução Escrita (Níveis I e II). Por outro lado, 26 crianças produziram narrativas mais coerentes na Reprodução Escrita (Níveis III e IV) do que na Escrita Livre (Níveis I e II). Este dado sugere que, de fato, a reprodução do conto favorece a escrita de histórias mais coerentes do que a produção livre. A explicação para isso é apresentada a seguir, quando se discute o papel da reprodução de textos na aquisição de habilidades narrativas em crianças.

\section{Discussão}

Examinando a influência do contexto de produção na construção da coerência em histórias escritas por crianças, nos primeiros anos do ensino fundamental, é possível identificar três resultados principais. Um diz respeito ao fato de que, em sua maioria, os alunos do $3^{\circ}$. ano produziram narrativas mais complexas que os do $2^{\circ}$. ano em ambas as condições de produção. Embora escolaridade e idade se confundam, a escolaridade parece ter sido o fator de maior influência na produção escrita de histórias. Spinillo e Martins (1997) mostram que crianças alfabetizadas tendem a produzir histórias orais mais coerentes do que crianças da mesma idade, porém não-alfabetizadas, e produções similares a crianças um ano mais velhas, porém recém-alfabetizadas.

O segundo achado diz respeito ao efeito do contexto sobre a produção escrita da criança. Observou-se que as circunstâncias em que a criança é solicitada a produzir uma história é fator importante no estabelecimento da coerência textual. No caso da presente investigação, mais do que a produção livre, a condição de reprodução escrita propiciou a produção de textos coerentes tanto entre crianças do $2^{\circ}$. como entre as do $3^{\circ}$. ano.

De acordo com Lins e Silva e Spinillo (2000), o textomodelo lido para a criança na condição de reprodução serve como apoio lingüístico que rege a sua escrita. Tanto naquele estudo como neste, na condição de reprodução a criança não apenas reproduz o tema, os personagens e eventos, mas também as propriedades lingüísticas do texto ouvido tais como: sua estrutura, suas convenções, os elos de coesão e coerência. Colocando em perspectiva os dados obtidos em estudos anteriores a respeito da aquisição de um esquema narrativo típico de histórias e os dados obtidos na presente investigação, é possível dizer que ao reproduzir um texto, oral ou escrito, a criança reproduz o modelo lingüístico que lhe é apresentado, aplicando-o à sua produção. Isso ocorre tanto em relação à estrutura do texto (esquema narrativo de história) como em relação ao estabelecimento da coerência textual. Esta discussão sugere que, apesar de serem fenômenos lingüísticos conceitualmente distintos, a coerência e a aquisição de um esquema narrativo estão associadas e parecem caminhar juntas no desenvolvimento da produção de textos.

O terceiro e último resultado deste estudo mostra que o efeito do contexto de produção sobre a escrita, no que tange ao estabelecimento da coerência, não parece ser o mesmo para todas as crianças. A susceptibilidade aos contextos de produção é pouco expressiva em crianças cujas produções são elementares e que encontram muita dificuldade em estabelecer a coerência em suas histórias (Domínio 1 do desenvolvimento do esquema narrativo) ou em crianças que estabelecem a coerência sem grande dificuldade (Domínio 3 do desenvolvimento do esquema narrativo). Assim, como ocorre na condição de reprodução escrita, ainda que um apoio lingüístico seja uma referência para a escrita de textos coerentes, é necessário considerar que uma habilidade narrativa bem desenvolvida deva prescindir deste tipo de apoio. Em contrapartida, observou-se que o efeito dos contextos de produção foi acentuado entre as crianças em um nível intermediário (Domínio 2 do desenvolvimento do esquema narrativo) para quem um textomodelo passa a ser um apoio lingüístico necessário para escrever textos coerentes e compreensíveis. É desejável que as crianças atinjam um nível de desenvolvimento lingüístico tal que sejam capazes de escrever histórias coerentes em todas as circunstâncias. Neste sentido, é importante que o texto-modelo seja internalizado para que possa ser aplicado a uma variedade de situações de produção de textos.

Esta discussão tem implicações educacionais importantes que colocam a reprodução de textos como uma atividade relevante para auxiliar a criança a internalizar 
as propriedades lingüísticas de textos diversos. A reprodução de textos pode assumir papel de destaque no contexto escolar, como menciona Teberosky (1995), devendo ser vista pelos educadores como uma atividade pedagógica de grande potencial, e não simplesmente como uma cópia. Uma vez que a reprodução escrita consiste na elaboração de um novo texto que guarda consigo aspectos referentes à estrutura e organização lingüística do texto-modelo, tal atividade em sala de aula pode ser uma ferramenta didática importante para o desenvolvimento das habilidades narrativas dos alunos que se encontram nos níveis intermediários do domínio do esquema narrativo. Assim, o emprego da reprodução de textos (lidos pelas próprias crianças ou para ela por um adulto) poderia ir além do propósito de ensinar a ortografia, a gramática e a pontuação e ter como função principal o desenvolvimento inicial da habilidade de produzir textos.

\section{Referências}

Beaugrande, R., \& Dressler, W. U. (1981). Introduction to text linguistics. London: Longman.

Bennett-Kastor, T. (1983). Noun phrases and coherence in child narratives. Journal of Child Language, 10, 135-149.

Bettelheim, B. (1979). A psicanálise dos contos de fadas. São Paulo, SP: Paz e Terra.

Cardoso, C. J. (2000). Da oralidade à escrita: A produção do texto narrativo no contexto escolar. Cuiabá, MT: Editora da Universidade Federal de Mato Grosso.

Coates, J. (1992). The negotiation of coherence in face-to-face interaction: Some examples from the extreme bounds. In M. A. Gernsbacher \& T. Givón (Eds.), Coherence in spontaneous text (pp. 41-58). Philadelphia, PA: John Benjamins.

Garcez, L. H. C. (2002). Técnica de redação: O que é preciso saber para escrever bem. São Paulo, SP: Martins Fontes.

Gonçalves, F., \& Dias, M. G. B. B. (2003). Coerência textual: Um estudo com jovens e adultos. Psicologia: Reflexão $e$ Crítica, 16, 29-40.

Goodwin, C. (1992). The negotiation of coherence within conversation. In M. A. Gernsbacher \& T. Givón (Eds.), Coherence in spontaneous text (pp. 117-137). Philadelphia, PA: John Benjamins.

Hudson, J. A., \& Shapiro, L. R. (1991). From knowing to telling: The development of children's scripts, stories and personal narratives. In A. McCabe \& C. Peterson (Eds.), Developing narrative structure (pp. 89-136). Hillsdale, NJ: Lawrence Erlbaum.

Koch, I. G. V., \& Travaglia, L. C. (2003). A coerência textual (15. ed.) São Paulo, SP: Contexto.

Koch, I. V., \& Travaglia, L. C. (2005). Texto e coerência (10. ed.) São Paulo, SP: Cortez.

Lins e Silva, M. E., \& Spinillo, A. G. (2000). A influência de diferentes situações de produção na escrita de histórias. Psicologia: Reflexão e Crítica, 13, 337-350.

Marcuschi, L. A. (1983). Lingüística de texto: Como é e como se faz. Séries Debates 1. Recife, PE: Editora da Universidade Federal de Pernambuco.

Marcuschi, L. A. (1998). Análise da conversação. São Paulo, SP: Ática.
Nóbrega, M. J. M. (1997). Produção de textos e compreensão leitora. Psicologia da Educação (São Paulo), 4, 61-79.

Pontecorvo, C., \& Ferreiro, E. (1996). Língua escrita e investigação comparativa. In E. Ferreiro, C. Pontecorvo, N. R. Moreira, \& I. G. Hidalgo, Chapeuzinho vermelho aprende a escrever: Estudos psicolingüísticos comparativos em três línguas (pp. 11-37). São Paulo, SP: Ática.

Pontecorvo, C., \& Morani, R. M. (1996). Looking for stylistic features in children composing stories: Products and processes. In C. Pontecorvo, M. Orsolini, B. Burge, \& L. B. Resnick (Eds.), Children's early text construction (pp. 229258). Mahwah, NJ: Lawrence Erlbaum.

Shapiro, L. R., \& Hudson, J. A. (1991). Tell me a make-believe story: Coherence and cohesion in young children's pictureelicited narratives. Developmental Psychology, 27, 960-974.

Spinillo, A. G. (2001). A produção de histórias por crianças: A textualidade em foco. In J. Correa, A. Spinillo, \& S. Leitão, Desenvolvimento da linguagem: Escrita e textualidade (pp. 73-116). Rio de Janeiro, RJ: Fundação de Amparo à Pesquisa do Estado do Rio de Janeiro.

Spinillo, A. G., \& Martins, R. A. (1997). Uma análise da produção de histórias coerentes por crianças. Psicologia: Reflexão e Crítica, 10, 219-248.

Teberosky, A. (1995). Compor textos. In A. Teberosky \& L. Tolchinsky (Eds.), Além da alfabetização (pp. 85-116). São Paulo, SP: Ática.

van Dijk, T., \& Kintsch, W. (1983). Strategies in discourse comprehension. New York: Academic Press. 